\title{
Dieldrin Poisoning in Man
}

\author{
WAYLAND J. HAYES, Jr., M.D., Ph.D.
}

\begin{abstract}
In certain programs, 10-20 percent of spraymen applying dieldrin for the control of disease vectors have been poisoned. Half or more of the reported cases were characterized by epileptiform convulsions. In general, the occurrence of poisoning parallels the intensity and duration of exposure but the factors influencing safety are too little understood. Ordinary, careful medical examination may offer the most sensitive and practical way of detecting preclinical poisoning, thus removing workers from exposure to prevent serious illness.
\end{abstract}

$\mathrm{T}$ THERE IS NO I)(OCI'T about the value of dieldrin in the control or eren eradication of certain vectorborne diseases. Infortunately, its use under certain conditions has led to poisoning of some of the workers who received $\mathrm{ex}$ tensive daily exposure for long periods. Information on the epidemiology and clinical course as well as the more recently described preclinical signs of this poisoning is bound to be of interest to those who use dieldrin or contemplate its use in control programs. This review was written bacause information on dieldrin poisoning has not been publicized widely.

Dr. Hayes is chief of the Toxicology Section, Technical Development Laboratories, Communicable Disease Center, Public Health Service, Savannah, Ga. He submitted this report to the Pan American Sanitary Bureau in his capacity as technical con. sultant to the bureau at the Symposium on Toxicological Investigations of Dieldrin held in Maracay, Venezuela, on May 15-16, 1957. The symposium was sponsored by the division of malariology of the Venezuelan Ministry of Public Health and Social Welfare.

The Spanish version of this paper is being published in the December 1957 issue of the Boletin de la Oficina Sanitaria Panamericana.
If it were possible, it would be desirable to state the conditions which have led to poisoning in one place and those which have permitted the safe use of dieldrin in another locality. I)ifferences in spray practices and in the personal habits of workers are obvious but not very enlightening. It is easy to find examples of "arelessiness" in the groups in which cases of poisoning have occurred, but the same is true among workers who have remained well. I)ieldrin has been used under strict supervision in some programs and with little supervision in other programs without producing poisoning. 'The number of workers involved or the amount of dieldrin really used by individual workers in these programs is frequently so small and the duration of use is so short that no useful information can be gained about the safe use of the compound in a large, continuing program.

It would seem that many reported cases of poisoning were the expected result of flagrant disregard of precautions suggested by the World Health (Organization (1) or other groups. It appears reasonable to conclucle that dieldrin should not be used where lack of water or some other factor makes the practice of cleanliness impossible. If the normal standards of hygiene are low, the use of dieldrin 
should be considered only if extensive supervision of the labor force can be exercised.

There is a need for time-motion studies of workers and measurements of their respiratory and especially their dermal exposures under different conditions.

Because of the need for dieldrin, any research would be a great contribution if it proved the value of some combination of procedures permitting safer use of the compound under practical conditions. As indicated below, an approach which appears hopeful is that associated with the early detection of preclinical illness.

Illness in Venezuelan spraymen caused by repeated exposure to dieldrin was first mentioned by Carrillo in 1954 (2). Although dieldrin was at first discounted as the cause of sickness, the true relationship was recognized very soon, according to A. Gabaldon (personal communication, 1954). Poisoning similar to that in Venezuela was also observed in Nigeria (3) and in Ecuador, according to information supplied by Lópes da Silva in 1956. In the United States, also, poisoning characterized by convulsions and associated with dieldrin and closely related compounds was observed in industrial workers (4).

Later and more complete studies of clinical poisoning have been reported by Blázquez and Bianchini (5-y). From the work which has been done, the following conclusions seem clear.

\section{Clinical Illness}

1. Under practical conditions of work in Venezuela, Ecuador, and Nigeria, clinical poi- soning has been reported in about 10 to 20 percent of spraymen (table 1 ).

2. The earliest observed poisoning occurred after a little less than 3 months of exposure. However, in the most comprehensive study available ( 7$)$, no cases occurred in less than 4 months of exposure, and only 2 percent of the spraymen exposed less than 8 months became sick. In general, the proportion of sprayers poisoned increased with the duration of their work (table 2). Twenty-six percent of workers exposed 8 months or more became sick. In consideration of the inevitable variation in the intensity of exposure of different workers and also the small number of workers studied with exposure greater than 2 years, the available data offer no indication of variation in individual susceptibility to poisoning although this possibility is not ruled out.

3. All of the reported cases were severe enough for the patients to seek medical aid. Half or more of the patients had convulsions. Although investigators have understandably reserved judgment in some individual cases, the epidemiology of the disease leaves no doubt that most, if not all, of the reported cases represent poisoning. In fact, it is most likely that some cases of real poisoning, especially mild ones, have been misdiagnosed and thus not reported.

4. Mild clinical illness caused by dieldrin poisoning is characterized by the following symptoms: headache (which is frequently persistent and not responsive to drugs), blurred vision, dizziness, slight involuntary muscular movements, sweating, difficulty in sleeping and bad dreams, nausea, and general malaise. (It

Table 1. Dieldrin poisoning cases in three countries

\begin{tabular}{|c|c|c|c|c|c|}
\hline Country & $\begin{array}{l}\text { Number of } \\
\text { spraymen }\end{array}$ & $\begin{array}{l}\text { Clinical } \\
\text { cases }\end{array}$ & $\begin{array}{l}\text { Cases with } \\
\text { convulsions }\end{array}$ & Fatalities & $\begin{array}{l}\text { Percent of } \\
\text { sprayers } \\
\text { poisoned }\end{array}$ \\
\hline $\begin{array}{l}\text { Venezuela. } \\
\text { Ecuador. } \\
\text { Nigeria. }\end{array}$ & $\begin{array}{r}285 \\
92 \\
40\end{array}$ & $\begin{array}{r}51 \\
8 \\
24\end{array}$ & $\begin{array}{l}22 \\
14 \\
24\end{array}$ & $\begin{array}{l}\mathbf{0} \\
\mathbf{1} \\
\mathbf{0}\end{array}$ & $\begin{array}{r}18 \\
9 \\
10\end{array}$ \\
\hline
\end{tabular}

1 Possibly underestimated.

2 One patient had a history of epilepsy.

Nоте: Venezuela-1.25 percent suspension is applied to porous surfaces and a 2.50 percent emulsion is applied to nonabsorbent surfaces at a rate of $1 \mathrm{gm} . / \mathrm{m} .{ }^{2}$ in each instance. Ecuador- 2.50 percent formulations are used at a rate of $0.5 \mathrm{gm} . / \mathrm{m}^{2}$. Nigeria- 0.68 percent suspension and emulsion and 1.37 percent suspension are used at rates of 0.27 and $0.54 \mathrm{gm} . / \mathrm{m}^{2}$. 
Table 2. Relation of poisoning to duration of exposure to dieldrin, Venezuela ${ }^{1}$

\begin{tabular}{|c|c|c|c|c|}
\hline \multirow[b]{2}{*}{$\begin{array}{l}\text { Months of } \\
\text { exposure }\end{array}$} & \multirow{2}{*}{$\begin{array}{l}\text { Number } \\
\text { of spray- } \\
\text { men } \\
\text { with } \\
\text { stated } \\
\text { months } \\
\text { of ex- } \\
\text { posure }\end{array}$} & \multirow[b]{2}{*}{$\begin{array}{l}\text { Number } \\
\text { of spray- } \\
\text { men at } \\
\text { hazard }\end{array}$} & \multicolumn{2}{|c|}{ Cases of poisoning } \\
\hline & & & Number & $\begin{array}{l}\text { Percerit } \\
\text { of those } \\
\text { at } \\
\text { hazard }\end{array}$ \\
\hline $\begin{array}{l}0-3.9 \\
4-7.9 \\
8-11.9 \\
12-15.9 \\
16-19.9 \\
20-23.9 \\
24-27.9 \\
28-31.9 \\
32-35.9 \\
36-39.9\end{array}$ & $\begin{array}{r}69 \\
38 \\
26 \\
54 \\
41 \\
45 \\
7 \\
1 \\
0 \\
4\end{array}$ & $\begin{array}{r}285 \\
216 \\
178 \\
152 \\
98 \\
57 \\
12 \\
5 \\
4 \\
4\end{array}$ & $\begin{array}{r}0 \\
5 \\
9 \\
14 \\
13 \\
4 \\
6 \\
0 \\
0 \\
0\end{array}$ & $\begin{array}{r}0 \\
2 \\
5 \\
9 \\
13 \\
7 \\
50 \\
0 \\
0 \\
0\end{array}$ \\
\hline $0-39.9$ & 285 & 285 & 51 & 18 \\
\hline
\end{tabular}

1 Modified from Blázquez and Bianchini (7).

is entirely possible that other syndromes exist. The poorly defined illness of the European superintendent described by Haworth (3) may well be a case in point.)

5. More severe illness is characterized by the symptoms already mentioned and also by stronger jerking of entire muscle groups leading to movement of some part of the body or the limbs or even causing the patient to fall. In extreme cases these movements are accompanied by momentary loss of consciousness.

6. The most severe, nonfatal poisoning observed so far has been characterized by one or more epileptic convulsions with loss of consciousness but without involuntary incontinence of feces or urine. One patient had more than 30 convulsions. Because patients are unconscious during seizures it is likely that some seizures have been overlooked.

7. The circumstances associated with the death of a sprayman in Ecuador are not known except that he was exposed to dieldrin and his illness was characterized by convulsions. (Animal experiments have revealed a form of dieldrin poisoning which, in the absence of treatment, is uniformly fatal. It is marked by convulsions, complete food refusal, and rapid loss of weight. Such poisoning would almost certainly occur in man under certain condi- tions but has apparently not yet been described.)

8. The convulsions and sudden falls associated with severe illness are of brief duration. Aside from these attacks and the wounds they may produce, signs of illness are not prominent even soon after a convulsion. However, by very careful observation, the following signs may be discovered in many cases of clinical poisoning: slight alteration of reflexes, incoordination (Romberg and other tests), nystagmus, tremor, sweating, dermatographia, and muscular fibrillations (which can sometimes be elicited by striking the muscle or, apparently, by hyperventilation). Occasionally, patients exhibit disorientation or change of personality. Tachycardia and arrhythmia are fairly common.

9. Following removal from exposure, all survivors showed initial improvement. However one patient suffered a recurrence of convulsions 84 days after his last exposure to dieldrin. Some other patients have required as much as 105 days for recovery. In view of these facts and the fact that it has been impossible to follow all cases, it is clear that dieldrin poisoning in man tends to be chronic, but the full extent of the chronicity is not yet known.

10. There is a broad relationship between intensity and duration of exposure, sickness, and the amount of dieldrin in the blood as determined by bioassay. However, the bioassay, as it has been used so far $(6-8)$, shows so much individual variation that it is of limited diagnostic value (table 3 ).

11. Electroencephalograms were abnormal in about half of the clinical cases studied by this method. But the absence of detectable abnormality in many cases, the small degree of abnormality in some other cases, the presence of abnormality in a few unexposed people, and the expense and difficulty of electroencephalography make it of limited value. Detailed information in the tracings has been given by Ducharne (9).

Cases clearly involving the ingestion of single doses of dieldrin have not been reported, but such cases have been published in connection with related compounds. Poisoning by aldrin in combination with a solvent was complicated by effects on the liver and especially on the kid- 
neys as well as the nervous system $(10,11)$. Poisoning of more than 59 persons by endrin eaten as a contaminant of bread involved the gastrointestinal system as well as the nervous system (12). (linical recovery following a single dose of these compounds has been prompt, although the electroencephalogram did not return to a normal reading for almost 5 months in the aldrin case. Similar results would be expected if dieldrin were eaten.

\section{Preclinical Poisoning}

In effort to detect preclinical poisoning has been reported by Winthrop and Felice (1.3). A total of 109 spraymen (about half of those employed in Venezuela at the time) were examined. Seventy-two of the 109 spraymen had been exposed to dieldrin for an average of 70 weeks and were currently exposed at the time of examination. Twenty-six of the 109 had been exposed for an average of 30 weeks but had had no contact with the compound for at least 10 weeks prior to the date of examination. In addition to the spraymen, $6+$ men without occupational exposure to dieldrin but otherwise as nearly comparable to the spraymen as possible were examined as controls.

The following symptoms and signs occurred more frequently in spraymen exposed to dieldrin for an average of 30 or more weeks than in controls: headache, blurred vision, diplopia, timnitus, dizziness, slight involuntary muscular movements, sweating, difficulty in sleeping and bad dreams, nausea, alteration of reflexes, incoordination, nystagmus, muscular fibrillations, and change in personality.

The parallelism of these symptoms and signs and those associated with clinical illness is remarkable and probably not accidental. It is important to remember, however, that the relationship has not been evaluated either by a statistical analysis of the data collected by Winthrop and Felice or by a practical test. A practical test would consist of an effort to prevent all poisoning severe enough to cause a workman to seek medical care. Serious poisoning could be prevented theoretically if workers were removed completely from dieldrin exposure as soon as they reached some critical level of preclinical effect.
Table 3. Bioassay index for various groups of workers in Venezuela ${ }^{1}$

\begin{tabular}{|c|c|c|}
\hline Group & Range & Mean \\
\hline Controls (5) & 20 & \\
\hline 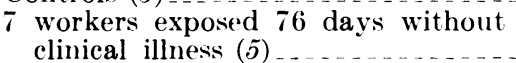 & $0-36$ & 1 \\
\hline $\begin{array}{l}9 \text { workers with grade I intoxication } \\
(5)\end{array}$ & $0-90$ & 53 \\
\hline $\begin{array}{l}10 \text { workers with grade I intoxication } \\
(6)\end{array}$ & $22-100$ & 69 \\
\hline 7 workers with grade III intoxication & $0-100$ & 71 \\
\hline $\begin{array}{l}16 \text { workers with grade III intoxica- } \\
\text { tion }(6)\end{array}$ & $8-100$ & 70 \\
\hline
\end{tabular}

${ }^{1}$ Recalculated from data of Blázquez and Bianchini $(6,7)$

2 Occasionally the death from natural causes of insects used in the tests will produce an index greater than zero.

The "symptom profile," the "sign profile," and the resulting "profile index" (1.3) are clevices for expressing results conveniently and they deserve serious consideration. However, these devices do not test the data. To be of use they must be based on areful examination of the patient. 'The profile index should be used or modified as convenience and experience dictate. Not necessarily related to the use of this index is the suggestion that technicians could be trained to administer systems reviews and even perform simple neurological examinations. Records obtained by technicians could be interpreted by a physician who would examine thoroughly those spraymen showing progressive or sufficiently serious abnormalities.

About one-third of the spraymen who were not sick showed some abnormality in their electroencephalograms $(9,1.3)$. It is of interest that abnormality of the brain waves may continue for more than $t$ weeks after the last exposure to dieldrin. However, for reasons outlined above, the test is of limited value. The usefulness of spinal fluid examination in the diagnosis of dieldrin poisoning is not established although the findings justify further study in laboratory animals.

Considerable study has failed to show any value of the following tests in connection with dieldrin poisoning: urinalysis, complete blood study, chest $\mathrm{X}$-ray, determination of visual fields, psychometric tests, or chemical determination of dieldrin in the blood. IDieldrin can 
be successfully analyzed after addition to blood in the laboratory (14). It may be that the difficulty of chemically analyzing dieldrin in the blood of patients lies in the problem of extraction and purification of the sample. Such problems are well known in comnection with the analysis of IDI'T in blood in contrast to the analysis of I)I'T in fat.

\section{Prevention}

Many of the papers mentioned above have ended with a list of recommendations regarding spray practices. 'The recommendations have generally been reasonable. Many of the authors stated flatly that dieldrin can be used safely in an insect control program if the recommendations are carried out. Perhaps this would be true if the recommendations were followed in practice. However, it is necessary to face the fact that (except by discontinuing the regular use of dieldrin) poisoning has not yet been eliminated in comnection with any insect control program which gave rise to dieldrin poisoning in the first place.

The limitations of present know ledge of dieldrin poisoning and failure to eliminate such poisoning must be kept in mind. It is equally important to remember that (although complete proof is not yet available) there is evidence that ordinary, careful medical examination by a physician (especially systems review and neurological examination) offers the most sensitive and most practical way of detecting preclinical poisoning. If preclinical poisoning is detected early and affected workers are removed permanently from dieldrin exposure, it may be possible that clinical poisoning can be prevented to a large extent. Furthermore, past failure does not eliminate the possibility that the protection of spraymen and, especially, the uncompromising education of those workers in personal hygiene will greatly reduce the incidence of dieldrin poisoning.

\section{REFERENCES}

(1) World Health Organization: Toxic hazards of pesticides to man. Report of a study group. Who 'Te(h. Rep: Series No. 114. Geneva, 19).6.
(2) Carrillo, S. J.: El empleo del dieldrin en Venezuela. Bol. ofic. san. panam. 3i: $76--81$, July 1954.

(.) Haworth, J.: (Observations on possible toxic effects of dieldrin on mammals. WHO/Insecticides/60. Genera, World Health Organization, 1956. Mimeographed.

(4) Nelson, E.: Allrin poisoning. Rocky Mountain M. J. $50: 4 \$ 3-4 \$ 6$, June 1953.

(.j) Blizquez, J., and Bianchini, (.: Intoxicación crónica ocupacional por dieldrin en el hombre. División de Malariologiá, Inirección de saluci Pública, Ministerio de Sanidad $y$ Asistencia Social. Maracay, Venezuela, 195. Mimeographed.

(6) Blizquez, J., and Bianchini, ('.: Intoxicarcion crónica ocuparcional por dieldrin en el hombre. Gac. Méd. de (aracas 63: 1-39), January-February 1956.

(i) Blazquez, J., and Bianchini, C.: Nuevos casos de intoxicación crónica ocupacional por dieldrin. IDivisión de Malariologiá. Dirección de Salud I'úblicar, Ministerio de Sanidad y Asistencia social. Maracay, Venezuela, 19et. Mimeographed.

(s) Carrillo. s. .J., and Blázquez. J. : Xenodeterminación toxicológicar de dieldrin en sangre. Bol. Ofic. san. panam. 39):296-299, September 195.).

(9) Ducharne, I'. I. I'.: Estudio electroencefalográfico de rociadores de dieldrin. Mimeographed report. presented at the symposium on Toxicological Investigations at the Division of Malariology. Maracay, Venezuela, 19.5.

(10) Spiotta, E. J.: Aldrin poisoning in a man. A. M. A. Ar(h. Indust. Hyg. \& O(c)11). Med. 4 : $560-566$, I lecember 1951.

(11) Spiotta, E. J.. and Winfield. I). I.. : Case report of aldrin poisoning with special reference to EEG and central nervous system findings. Electroencephalography, Montreal $4: 215-217$, May 195:).

(1.2) Iavies, G. M.. and Lewis, I.: Outbreak of foodpoisoning from bread made of (hemically (ontaminated flomr. Brit. Med. J. No. t!m!) : 394-398, Aug. 18, 1956.

(1.3) Winthrop, (x. J., and Felice, J. R. : In estudio clínic·o-toxicológico con rociadlores dé un insecticida de hidrocarburo clorado. Nimeographed report, presented at the symposium on Toxicological Investigations at the Division of Malariology. Maracay, Venezuela, 1957.

(14) Reynolds, J. (x.: Determination of dieldrin in blood. Mimeographed report, presented at the Symposium on Toxicological Investigations at the Invision of Malariology. Maracay. Venezuela, 19.iт. 


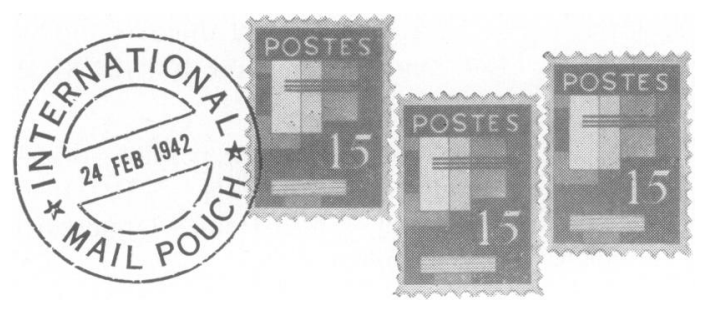

\section{Baby Show in Mafrak}

Ninety healthy infants were contestants and 14 received prizes in the baby show held at the clinic at Mafrak, Jordan. Child care is improving from the clinic's system of teaching mothers in groups. This system reaches more mothers and babies than individual instruction.

-Elizabeth C. HilbonN, formerly chief nurse, U.S. Operations Mission, Jordan.

\section{Fathers and Sons}

"It was good enough for my father and it's good enough for me" was the gray-bearded village council members' reply when we tried to get them to install a water distribution system.

In the Iranian village where this happened I spoke especially to the few young men on the council. "It is hard to estimate the value of the life of a young child," I said, "but the cost of a water system does not begin to approach it."

Every one of the young men came up to see me after the meeting. Such a thing was good for them, they realized, but they were few and because of their age, had little to say about the running of their village.

In other villages we visited during our trip through Fars Ostan (province) in southwest Iran, we got many requests for water distribution systems. Though some lacked the money to put in a new system we were able to help them with hand pumps or repairs to the old system. Some villages wanted bathhouses, and we promised to come back and make preliminary sketches for drafts to be approved later.

A few years ago persuading people to change their bathing habits was almost impossible, but with newly developing understanding, old customs are changing. For instance, in one village a local contractor building a bathhouse with a common bath, voluntarily switched to a shower system after talking with the district's sanitarian aide.

We made the trip to see the sanitarian aides' work, to persuade municipalities to send employees to the Palasht School of Sanitation, and to encourage towns to spend 0.005 percent of their budgets on health and sanitation.

Several times we visited schools and invariably were asked to question the children. The majority knew the answers to questions such as "Is it better to be clean or dirty?" or "What is the cause of malaria?" and "What should be done about it?" The hope of Iran lies in the young.

-DAvid S. REID, Shiraz provincial sanitary engineering adviser, U. S. Operations Mission, Iran.

\section{Sergipe's Health Centers}

Ten health centers were opened during a tour the Governor of Sergipe, Dr. Henrique Maia Penido, superintendent of Serviço Especial de Saúde Pública, and I made of this state in northeast Brazil. SESP and the Sergipe Health Department signed a contract only a year ago. Sergipe had never before allocated so much money to health.

In the interest of economy, not one of the centers. was constructed from the ground up; some halffinished or vacant building or remodeled home was. used. All 10, either separately or in pairs, are staffed by full-time doctors, nurses, and home visitors, an innovation for Sergipe.

-E. Ross Jenney, M.D., chief, Division of Health and Sanitation, U. S. Operations Mission, Brazil.

\section{Vaccination for Chickenpox}

People in Liberia find it hard to understand why we don't vaccinate against chickenpox. Their young children are apt to die from chickenpox complications such as pneumonia or superimposed malaria.

Outbreaks of the disease are often reported as. smallpox. When we had no word from our dresser in Kokoyah for several months, the reason given was that he had gone on patrol to vaccinate everyone in his chiefdom against smallpox and chickenpox.

-E. L. Masthoff, M.D., medical officer, U. S. Operations Mission, Liberia. 